\title{
CHALLENGES IN TEACHING-LEARNING HIGHER MATHEMATICS REMOTELY AT RIGA TECHNICAL UNIVERSITY IN COVID-19 PANDEMIC
}

\author{
Ilona Dzenite, Sarmite Cernajeva, Elena Ligere \\ Riga Technical University, Latvia \\ ilona.dzenite@rtu.lv, sarmite.cernajeva@inbox.lv, jelena.ligere@rtu.lv
}

\begin{abstract}
This article overviews difficulties and challenges faced by mathematics professors and students at the Riga Technical University due to the necessity of enforced and immediate transition from the classroom to distance learning. It also contains research focused on finding an optimal way of teaching mathematics when only distance education is available. The research is based on surveys completed by students and mathematics professors about the experience gained during the spring and autumn semesters of 2020. The methods found through the research can be applied in teaching related subjects such as natural sciences and engineering.
\end{abstract}

Keywords: higher mathematics, distance education, challenges.

\section{Introduction}

In the spring of 2020, the routine of daily face-to-face teaching was turned upside down, as the spread of Covid-19 drastically changed the daily routines of both students and teaching personnel. Professors and students faced significant difficulties and challenges due to the necessity of enforced and immediate transition from the classroom to distance learning in almost all universities of the world. It quickly became apparent that assumptions, which are normally part of our professional and educational life, did not correspond to the new reality.

The transition to distance learning was associated with many problems including technical ones, such as the availability of the necessary equipment (computers, tablets) for both students and teachers, the absence of a good Internet connection at home for everyone, problems with old electronic devices (on which it is not possible to install all necessary software and applications, or they do not run smoothly), problems of choosing and mastering platforms for online teaching-learning, etc.

The main question, when switching to remote teaching, was how to adapt the curriculum model of classroom teaching to online teaching. A particularly difficult transition was for natural sciences such as mathematics, physics, chemistry, etc., as well as engineering courses, where classroom or laboratory contact hours are important (e.g., tutorials in mathematics and other natural sciences, laboratory work in chemistry, etc).

In times of crisis, when the normal rhythm of life is disrupted and various constraints are observed, many feel tension, anxiety, anger, grief or depression. Such emotions are understandable, but it is very important to do everything possible to help yourself and your peers. The process of adaptation of the university to the modern reality of mostly distance education started almost 1 year ago. At present, students and professors have already encountered both positive and negative experiences.

During the last year, many articles have been written about the experience of the transition to distance learning at universities in different countries [1-2], the challenges that universities faced, and also analyzed the quality of distance learning. For example, article [2] observes the challenges of distance learning caused by the imperfection of distance learning regulation, insufficient development of theoretical backgrounds and methodology of distance learning. Besides, risks in the quality of education and threats to the health of students in the realization of distance learning are also analyzed.

Student life has always supposed to include time for out-of-class learning activities, when a student should continue learning after he/she leaves the lecture given in a classroom. There are many factors which make out-of-class activities less effective, such as weak time management and self discipline, lack of supervision and instant feedback, lack of encouragement and motivation [3]. At present, when the whole study process is remote, the questions around out-of-class activities have become even more significant. In spring 2020, it was felt that many students failed to drive themselves to cope with the set problems or failed to solve them without the presence of a tutor. How can professors better engage students to continue learning, to learn efficiently and gain knowledge in every subject of their syllabus?

It is important to develop new remote learning models that can help learners find new regimes of learning and ensure that they do not loose motivation to study. When developing improvement methods, one should not only take the opinions and experiences of teachers into account, but also the opinions of 
students are essential. Students and professors are two sides of the same study process. They should share their difficulties and challenges, should highlight the advantages and disadvantages of distance education, and should identify both opportunities and the things which caused them the biggest problems.

In some articles, the research was based on a survey among teaching personnel, but other articles presented results obtained from students' surveys. A series of articles, which are based on surveys of students, provides an analysis of how students are prepared for distance learning [4-8], how students assess distance learning and how satisfied they are with distance learning at different universities. The impact of the COVID-19 pandemic on the quality of the educational process by using the survey of students is discussed, for example, in [9]. The study [5] analyzes the influence of experience, subjective norms, enjoyment, computer anxiety, and self-efficacy on students' expectations in the context of distance learning during the COVID-19 pandemic. Article [6] focuses on the perception of students of two universities of Romania regarding online learning, their capacity to assimilate information, and the use of E-learning platforms. In [10] perceptions of engineering students towards five specific course units forming part of engineering degree courses at the University of Burgos (Spain) were evaluated to assess the quality of online teaching, and also compared with their perceptions of face-to-face teaching of the course units prior to the outbreak of the pandemic.

It is already clear that the Covid-19 crisis will have a long-lasting impact on the provision of study and training, meaning that the role of digital education will continue to increase in the future. For education providers, this means finding a good balance between the learners' social inclusion through face-to-face teaching and adapting to the changing circumstances of face-to-screen teaching. Therefore, the analysis of the experience during switching to remote work, as well as the assessment of the experience gained in distance teaching is essential.

Specific issues have arisen in transition to the remote teaching of mathematics at universities. Mathematics is one of the most fundamental sciences, and it is a basic discipline in any technical university. Mathematics is the language of the universe which can explain our physical world. It is also a language which both humans and computers can understand. On other hand, mathematics is often a difficult subject for students who do not learn and use it on a regular basis. In contrast to humanities subjects, mathematics needs to be "drilled". Students should solve many different tasks, choose proper solving methods and think clearly, and solve and defend their solutions. In mathematics, understanding of study material is very important. It also should be noted that to understand the material, tutorials are needed, at which students together with their tutor solve problems step by step.

In some articles based on surveys for university professors, the readiness of mathematics teachers for remote teaching and success in the transition of teaching mathematics from face-to-face teaching to distance teaching at certain universities was analyzed [11-12]. For example, quantitative and qualitative analyses were made in article [12], which observed the way of teaching that mathematics professors of the Sicilian State University have used to adapt to the new teaching modality during the first wave of the COVID-19 pandemic. The article presents the research on how the mathematics professors faced the challenge of teaching via distance education and also reveals their beliefs related to teaching mathematics at university level, noting what has been advantageous or disadvantageous for them in distance teaching.

In this paper, the authors discuss significant difficulties and challenges faced by mathematics professors and students at the Riga Technical University (RTU) due to the necessity of enforced and immediate transition from the classroom to distance teaching-learning of mathematics.

For RTU mathematics professors, questions about the best ways of explaining mathematics topics to students and about the best ways of organizing remote tutorials, as well as how to objectively assess students' knowledge, have become very significant and relevant. The professors feel responsible for the knowledge they deliver to students remotely and do their best to provide the same quality of mathematics education as before the pandemic. Despite all the difficulties, the mathematics professors have been able to reorganize their work so that the study process has continued, while it is being continuously improved. During this time, the professors have received a lot of support from students who have been very understanding, ready to advise and, most importantly, actively studying in the new conditions, as evidenced by the high attendance rate. 
In this article, the authors also present the research on finding an optimal way of teaching mathematics at the university when only distance education is available. The research is based on surveys offered for RTU students. The aim of the survey for students was to learn the students' point of view on distance learning, and the difficulties and challenges faced by them in understanding what students need to better master mathematics through distance learning. The questions about improvements in distance learning were highlighted by taking into account the results of the survey and discussions among mathematics professors of RTU.

Even before the Covid-19 pandemic, information and communication technologies were widely used in the field of higher education and training [13-14]. The development of information technology affects the environment of both teaching and learning mathematics [14-15]. Since the 2007/2008 academic year, the Riga Technical University has been using the ORTUS e-learning platform, based on the MOODLE (Modular Object-Oriented Dynamic Learning Environment). After a one year period of successful testing of the ORTUS platform, all the academic staff of the Department of Engineering Mathematics (DEM) of RTU have been obliged to use ORTUS in maintaining and completing e-learning courses. ORTUS is an environment containing general information about the university life and events, with e-courses relevant to every study subject taken by a student in every semester. This platform had previously been facilitating the study process for students through convenient access to electronic study materials, electronic tests and actual course information, but in the pandemic, ORTUS has become a "safety net" for RTU students, professors and administrative personnel. On ORTUS, any professor can create their own e-learning sub-course, a separate environment with limited access only for those students who have been enrolled to this professor's lectures, where students can collaborate with their course-mates and the professor, where students get links to Zoom lectures and tutorials, where there are tools for students to upload homework, written tests and examination papers, and receive corrected and marked feedback from the professor. ORTUS has made the work of professors more effective and the study process readily available for students learning remotely, to enable them to learn all that is required for successful completion of the subject [14].

\section{Methodology}

The capacity for adaptation is the greatest challenge for the university in the current conditions. In order to find out answers to the questions "What experience has our university gained? What new professional challenges and skills have RTU professors of mathematics gained? How are students coping with distance learning of mathematics? What is the preferred model of a study process for students? " and also to understand how to adapt our model of face-to-face teaching to online face-toscreen teaching, we asked the students and our colleagues, the professors of the Department of Engineering Mathematics, to participate in a survey.

A survey is a method of gathering initial information, which involves asking the research group (students) written questions that contain the research problem at an empirical level. Nowadays, survey methods are used to study issues concerning people [16]. The survey method is one of the most effective ways to obtain a variety of information - about how people think, about their wishes and needs, views, attitudes and opinions. Individuals and organizations conduct surveys primarily for one of the following purposes: (i) they want to influence or persuade an audience; (ii) they want to develop or modify a product or service that will be offered to the relevant target audience; (iii) they want to understand and anticipate people's behaviour in certain circumstances, because that is necessary for academic research or professional work [17]. One of the methods for a survey is a questionnaire. A respondent must independently fill in a questionnaire, and it is important that the respondent understands the questions clearly. The questionnaire method was used for our survey.

The surveyed students were students who in 2019/2020 academic year had an autumn semester of normal classroom study and a spring semester of distance learning. We continued teaching mathematics to those students in the autumn semester of 2020/2021, where the first 7 weeks were of classroom teaching. Regarding the mathematics professors, we share our challenges and innovations with each other weekly in order to find the optimal way of teaching and assessing. In total, 115 students of the Faculty of Mechanical Engineering, Transport and Aeronautics, Faculty of Civil Engineering, and the Faculty of Power and Electrical Engineering participated in the survey which consisted of 16 questions. 
The questionnaire for the mathematics professors was carried out in the form of individual interviews conducted by phone or via the ZOOM platform. The professors were asked the same questions as the students in their survey about remote study processes. The questions were about the expediency of homework and remote control tests, about the level of objectivity in assessment of knowledge, about the preferred method of giving/receiving study materials, tutorials and lectures in remote teaching/learning. Additionally, the professors were keen to share their other teaching experiences, to suggest methodology which can be implemented into the remote study process, to share assessment experiences and ways to prevent or reduce cheating by students during exams and remote control tests. It has been noticed that the rate of cheating has been increasing greatly.

To analyze the obtained data, a qualitative approach was used with the emphasis on relatively small amounts of information, and on using the Likert scale to determine the level of consent of the respondents. Such a methodology of creating a survey sample set allows us to analyze the obtained data in various important ways.

\section{Results and discussions}

Regarding the quality of remote education during the pandemic and the knowledge acquired by students, this is not only a question about providing well-organized lectures and tutorials on a daily basis, but also a question about a proper and fair assessment system. In distance education, questions about the objectiveness of remote assessment of students' knowledge are very important. Remote assessment has become a new experience for many universities and professors all over the world, and it also presents many challenges, particularly when safeguarding academic integrity [18]. The paper [18] reviews assessment security in the digital domain and critically evaluates the practices from different universities in safeguarding academic integrity, including associated challenges. For example, invigilated assessments are often considered as more secure, but when done remotely detecting cheating would be significantly more challenging.

The question of academic integrity started to be considered by mathematics professors of RTU when assessing their students' remote tests, which were done without video invigilation. The professors noticed that previously weak students began to submit high quality papers, while previously successful students began to get lower grades than they had during face-to-face classroom tests. That fact made the professors reconsider the necessity of "blind" remote test, i.e., tests without video invigilation, taking into account the pressure on time of professors undertaking distance teaching and assessing. This question was addressed to students and mathematics professors in the survey and is considered in the current paper.

In contrast to humanities subjects, where it is sufficient just to speak to a student and evaluate his/her knowledge level in the subject, to evaluate the level of knowledge in mathematics, a professor has to give tasks which must be solved on paper, in hard copy. Conventional face-to-face assessments, when control tests and exams on mathematics are taken in the classroom under the direct supervision of a professor to make sure that each student has done the set work by themselves with no help from others, and that only formulas are used for solving mathematical problems. In a remote assessment system there are many technical, physical and human problems which make it easy for more and more students with a poor knowledge level to pass tests and exams successfully but unfairly [18]. A very strict video invigilation could be a solution, but it meets significant obstacles, such as poor Internet, unsuitable webcams (or their complete absence), small monitors or only one monitor, and the low number of students who can be examined at the same time. This leads to time problems: how much time does a professor need if his/her 200 students should be divided into groups of 15-20 students for each test?

During a semester, first year students normally have 6-8 written control tests on mathematics. Taking the above-mentioned obstacles as the reality, in distance learning, the tests were mostly written by students without a video invigilation but just within a restricted time. The completed tests were then submitted via the Internet. It is clear that in such conditions, instead of the norm of allowing only formulas, students could have used anything: formulas, samples of solutions, online calculator and, most tragically, paid solutions that were completed and even submitted by someone else. Let us see from the survey what students think about control tests written remotely. One can see from Fig. 1 that only $20 \%$ of the students who wrote the control tests on their own, used only formulas, i.e., the students who fulfilled the course requirements and wrote control tests the same way as they would do them face-to- 
face in a classroom, while other students used formulas together with other available materials, such as samples of solving and textbooks.

MATERIALS used by students during control tests

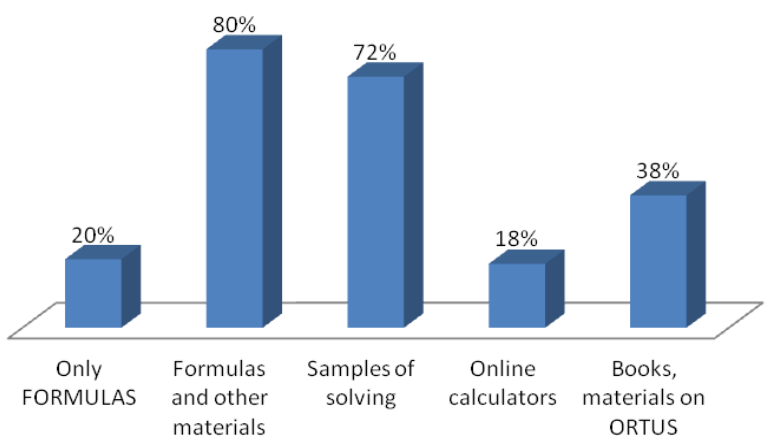

Fig. 1. Materials used during remote control tests
Does the grade for Control TESTS written remotely reflect the student's real knowledge?

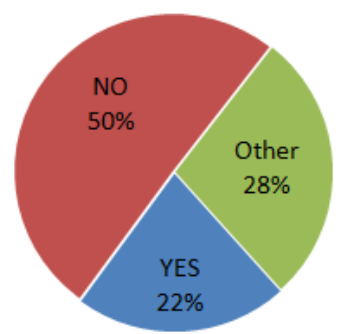

Fig. 2. Students' opinion about remote control tests

Besides, attention should be drawn to the fact that $50 \%$ of students consider that grades for the remote control tests written without strict video invigilation do not reflect the student's real knowledge (Fig. 2). However, most of the students consider that even remote control tests are still needed, as they help master the material and be better prepared for the exam (Fig. 3).

Do you think it makes sense to do Control TESTS that are written remotely?

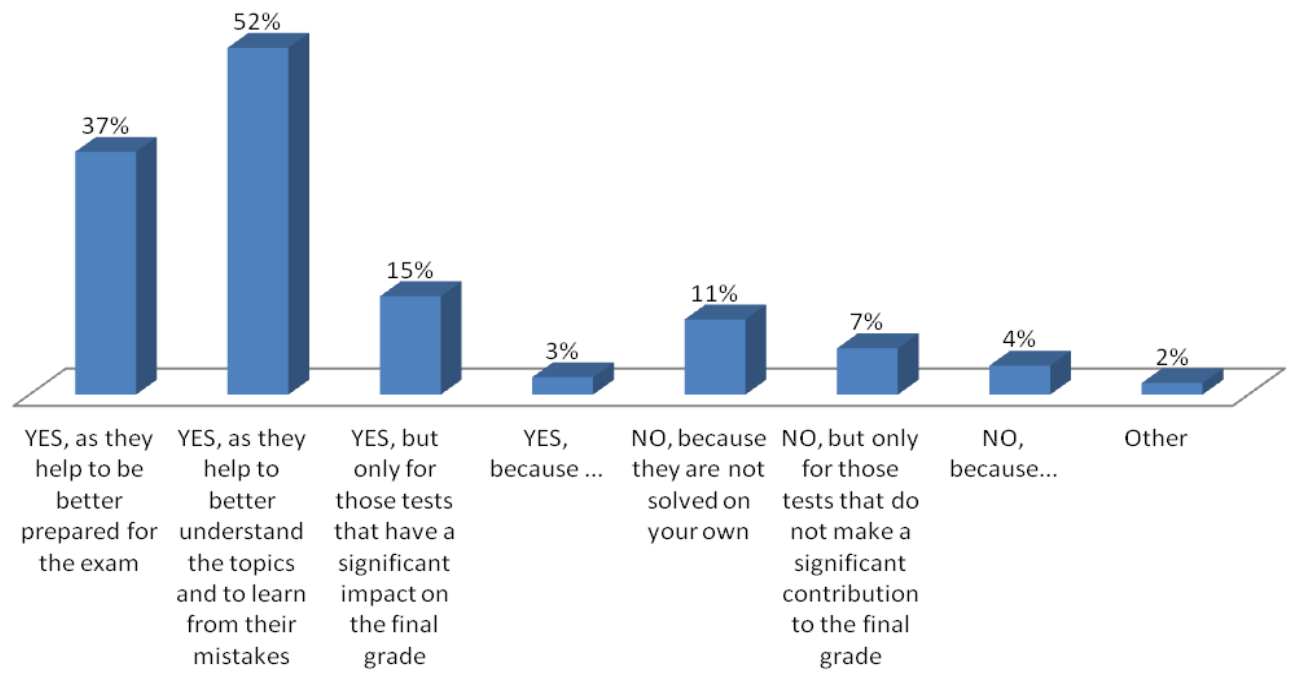

Fig. 3. Students' opinion about necessity of remote control tests

There is no doubt that control tests help students be better prepared for the exam: to practice solving tasks faster than it normally takes in homework, to better understand the topics and to learn from their mistakes, although, many students consider that the homework alone is sufficient in order to achieve the same purpose. In the previous conditions of classroom tests, the grades obtained from control tests contributed $35-40 \%$ to the final grade in mathematics, but the evidence from the survey is that in distance learning this quota should be reduced to $15-20 \%$ to be comparable with the grade for homework, which makes 10\% of the final grade. This "evaluation formula" has been used since the 2017/2018 academic year at the Department of Engineering Mathematics (DEM) of RTU in order to encourage students to learn continually and deeply, and to get results which rely on a student's knowledge rather than on their luck during the exam. 
Continuing the discussion about remote assessment, and after trying different approaches during last year, mathematics professors of DEM have found a very good model for conducting the examination on mathematics during pandemic conditions. The online examination model consists of 3 parts: The $1^{\text {st }}$ preliminary part is oral when a student is required to answer several brief questions about the main topics and solve several elementary tasks, which do not require any long consideration from the student but show the student's preparation level for the exam, and his/her ability to successfully solve the main tasks of the course. If the student fails the pre-exam, then he/she fails the whole exam. The $2^{\text {nd }}$ main part is when a student receives the exam tasks, solves them and submits the solutions on ORTUS within a limited time. The $3^{\text {rd }}$ part is the exam defence when the professor speaks to the student and may ask the student to explain some parts of his/her solutions and the methods used. The defence can influence the final grade of the student, i.e., may increase or decrease the grade. Moreover, all parts of the examination take place under strict video invigilation when a webcam must be located in a way that allows the professor to always see the student, the student's hands, the desk and PC monitor, and when any suspicious behaviour from the student, loss of the sound or video for more than 1 minute, let the professor stop the exam, but the student fails the exam. In particular, such strict exam conditions are recommended for students with debts in math because a high percentage of these students will try to cheat during exams. For current year students, who actively worked during the semester, the online examination may have only 2 steps: task solving and defence. Online examination with strict video invigilation is extremely time-consuming, but the most responsible professors use only this kind of examination, while waiting for the time when a traditional classroom examination can be possible again.

Another question is about homework. In mathematics, the more you solve, the better your results. Thus, homework is an important part in self-preparation for tests and exams for students; it is also the way to a better understanding of the topics. This is not the first survey that we have suggested to students and students continuously acknowledge the necessity of homework, but in distance learning, the frequency and saturation of homework should be adapted to conditions where students have less supervision and less stimulating and motivating factors around them. Most of the mathematics professors of RTU have concluded that homework is good to be given weekly, not only after finishing the corresponding topic. The surveyed students mostly think the same. To deliver the best education to students in distance learning, the professors' days have become fully dedicated to educational work, which asked and continues to ask for a very large investment of time. This is due to the fact that most of the tasks that already exist are not suitable for distance learning, so that everything has to be re-created and increased in numbers for distance learning. The increased amount of homework assignments solved by students leads to additional time that a professor needs for correcting and marking.

One of the aims of the students' survey was also to understand how difficult distance learning is for students. In the survey, students were asked about the difficulties such as poor self-organization, poor Internet, only having access to a shared computer, the absence of a personal room for study, etc. The distance learning was difficult or even very difficult for $65 \%$ of the surveyed students. Moreover, one of the essential problems for students was and remains poor self-organization (Fig. 4).

The professors have been continuously adapting remote teaching methods in order to help students, but it was felt that many students failed to drive themselves to cope with the set mathematical problems or failed to solve them without the presence of a tutor. As a result, the learning process had to be slowed down a bit in order to not run too far ahead of the student. Taking into account the wide range of digital tools available, the teaching staff used a variety of opportunities to implement the teaching process. Digital tools provide great opportunities to read, to study and discover, as well as to search for connections, to analyze and to communicate. However, on the other side, the issue of technical underequipment became a common problem both for students and professors, because the assumption often made in professional and educational life that everyone has a good Internet connection at home, that electronic devices with various new applications and conferencing software are running smoothly, does not correspond to reality (Fig. 4). Both students and professors highlighted the physical difficulty of spending many hours at the computer. While for students it is a problem of staying focused on a lecture in front of a PC monitor, for professors it is a day-long non-stop writing, commenting, correcting solved tasks and homework, and answering questions for each student individually. 

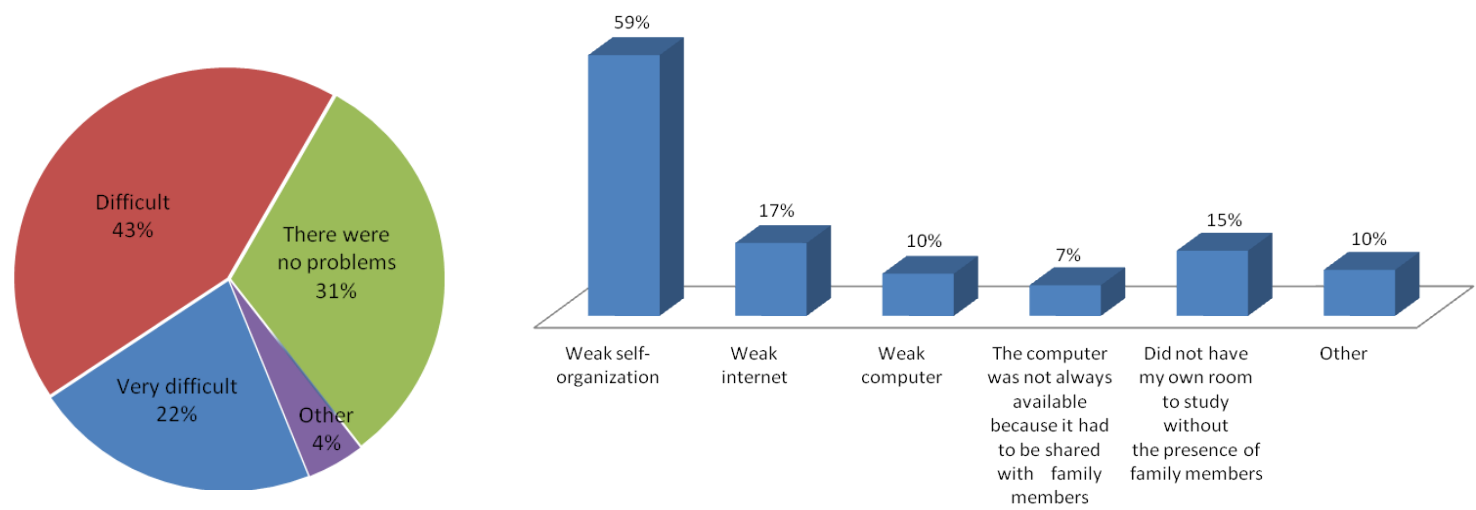

Fig. 4. Problems encountered by students in distance learning

The survey shows that students quite often have been listening and participating in tutorials via their smart phones (Fig. 5). This is not acceptable for mathematics and natural sciences, where students are required to make notes, solve tasks and be fully involved in the process. As a consequence of all the above-mentioned factors, the results of students in remote education has decreased in comparison with traditional classroom education (Fig. 6).

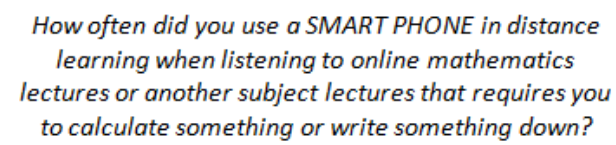

How often did you use a SMART PHONE in distance learning when listening to online mathematics lectures or another subject lectures that requires you to calculate something or write something down?

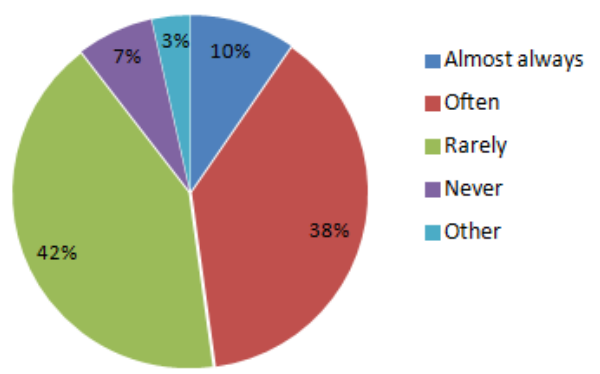

Fig. 5. Use of smart phones by students

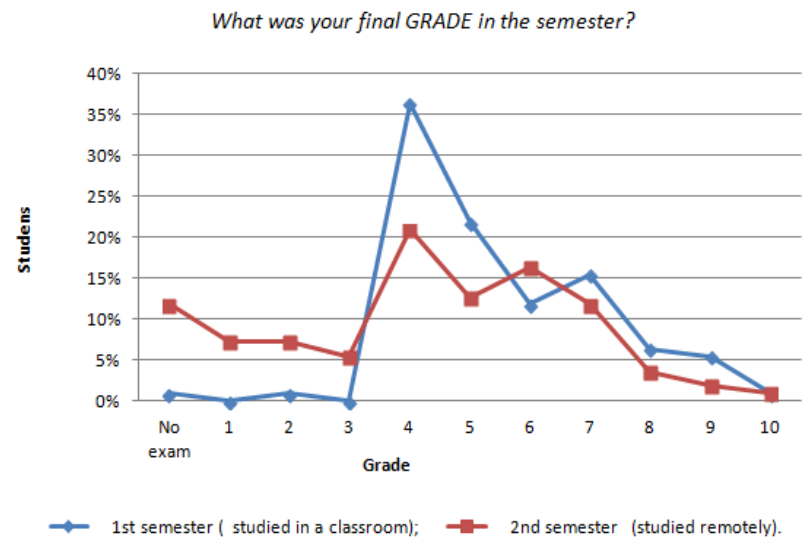

Fig. 6. Students' final grades in mathematics for participating in online mathematics per semester

Despite all the difficulties, both students and teachers have found similar advantages in distance learning. Many surveyed students highlighted the opportunity to sleep longer, not wasting time for commuting to and from university, the silence during lectures, a study regime organized by yourself, as well as silence during teaching and learning. The professors also have highlighted the following positive aspects: mastering a new model of cooperation with students in the learning process and learning to work on different platforms while improving their skills in technology. As some visible benefits of distance learning, the professors consider the skills gained due to learning and use of different platforms and tools which they had not used before, and the quietness of working from home that allows you to work more productively. To implement the learning process, the professors used all available equipment: smart phones, laptops, graphical tablets, desktop computers, and different e-learning platforms: Zoom, MS Teams, Moodle environment, Google tools; for communication with students Zoom online consultation, E-mail, Whatsapp, special tools on Ortus to submit papers with solutions, etc. (Fig. 7). The probable benefit of saving on travel time to and from work has in fact been negated by the abnormal increase in the workload of mathematics professors in distance teaching, so that everybody is looking forward to exchanging the currently overbooked days of teaching and assessment from home, 
for a return to the time spent on commuting, which is noticeably less, even for professors coming from other cities.

Another aim of the students' survey was to understand which teaching models and what type of lectures are the most optimal during distance learning and in general, from the students' point of view. Concerning the consultations, the majority of the surveyed students $(62 \%)$ highlighted that the best option is direct communication with a professor during online consultations via Zoom or MS Teams platform (Fig. 7).

\section{What form of mathematics CONSULTATION do you think is the best in distance learning?}

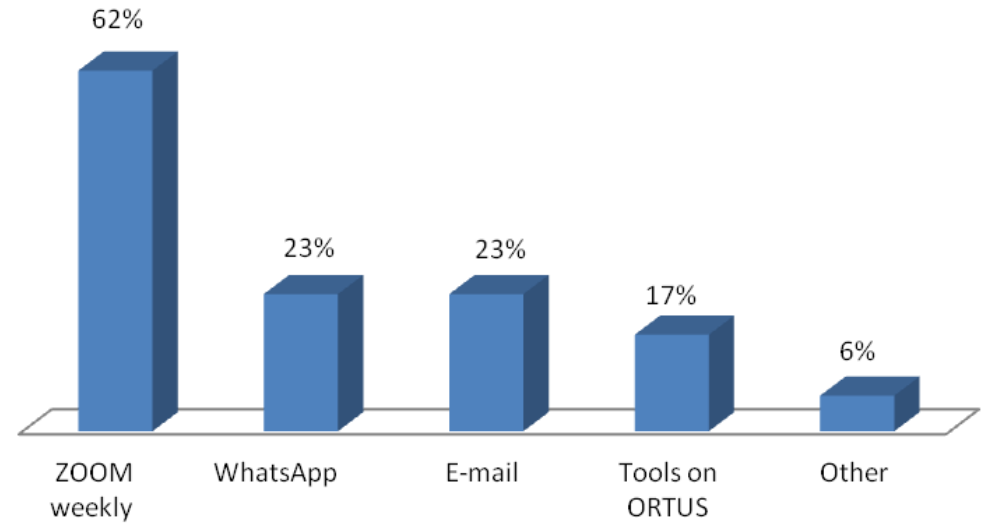

Fig. 7. Students' choice of consultations on mathematics during distance learning

It follows also from the students' answers that for students the best types of lectures in distance learning are both online lectures given on Zoom or another platform for video conferencing, where a professor writes and explains the material step by step and solves practical exercises, but does not show the pre-written in advance solutions, and the recorded video lectures, in which materials and practical exercises are written step by step with oral explanations (Fig. 8). Besides, the mathematics professors have pointed out that the best option for distance learning is online classes via platforms for video conferencing and, moreover, the students understand mathematical tasks better, if a professor solves and writes the steps of solution in real time on a screen.

Which type of LECTURES do you think is the best in distance learning? (rated from 0 to 5)

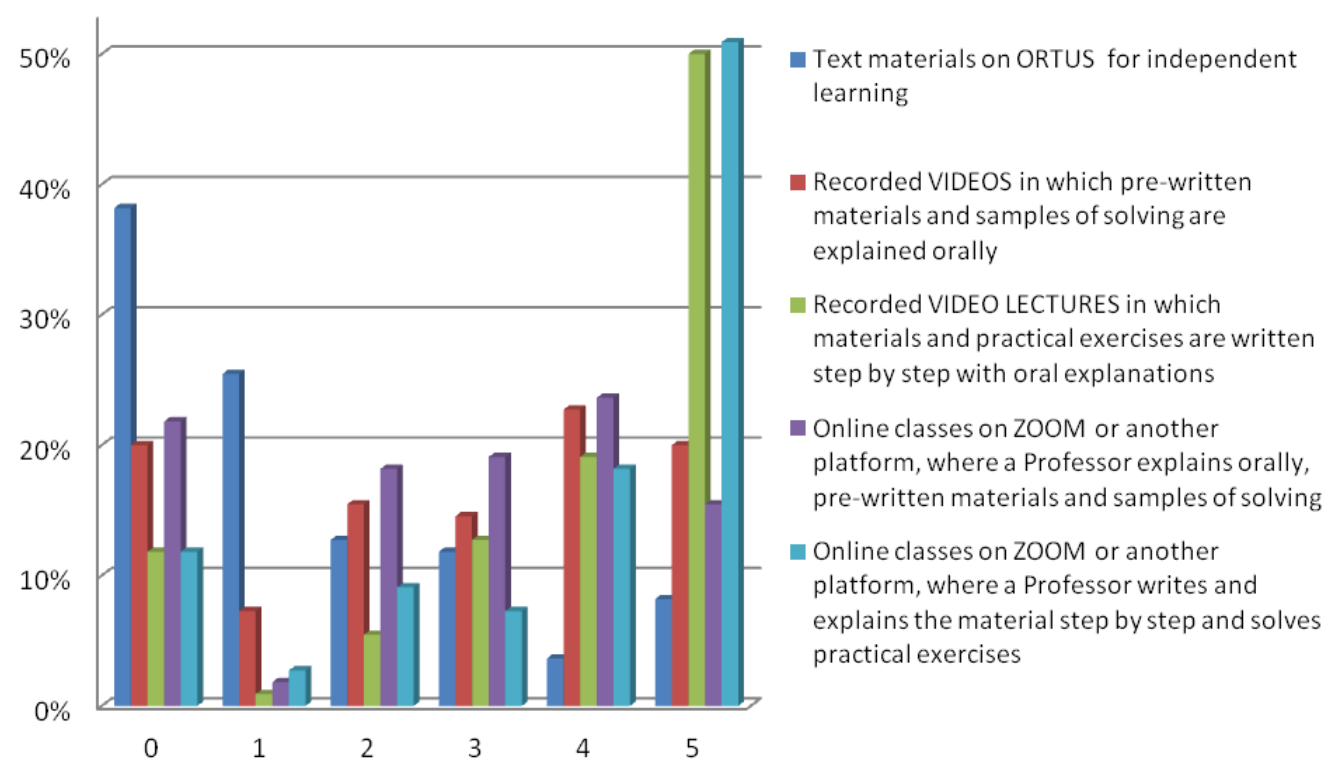

Fig. 8. Students' choice of a lecture type for remote mathematics 


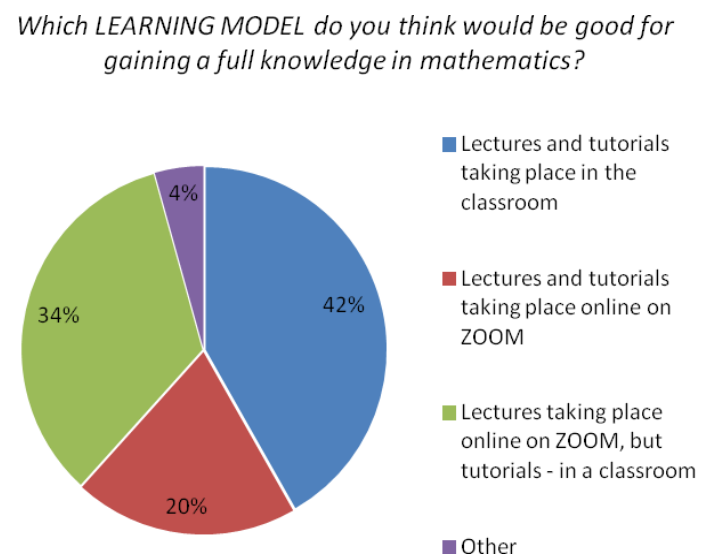

Fig. 9. Students' choice of a learning model

It is to be noted that the majority of the surveyed students (42\%) consider that classroom lectures and tutorials on mathematics are the best option for learning mathematics. However, $34 \%$ of students would like to have online Zoom lectures, but tutorials should take place in the classroom (Fig. 9). Thus, the face-to-face teaching remains the best form of education in the opinion of students and professors. All the above-mentioned means that in distance learning the best option for students to master mathematics is direct contact with students via online platforms, together with regular homework and control tests.

\section{Conclusions}

1. Difficulties and challenges faced by mathematics professors and students at the Riga Technical University due to the necessity of enforced and immediate transition from the classroom to distance learning were overviewed.

2. The results of the research focused on finding an optimal way of teaching mathematics in distance education were presented.

3. The qualitative and quantitative research was made on the basis of the questionnaire method in the form of a survey conducted among two groups of respondents: students and professors of mathematics at the Riga Technical University.

4. The quantitative results, presented graphically, explain similarities and differences between the opinions of students and professors regarding distance education, advantages and disadvantages, challenges they met.

5. Analyzing the research results, several models of teaching were revealed as the most suitable for successful remote explanation of mathematics. The importance of homework and remote control tests for understanding the material was highlighted.

6. Due to the increase of cheating opportunities from students during remote assessments, the issue of academic integrity has become essential. One form of remote examination that gives the possibility to estimate objectively the students' real knowledge was suggested.

\section{References}

[1] Almazova N., Krylova E., Rubtsova A., Odinokaya M. Challenges and Opportunities for Russian Higher Education amid COVID-19: Teachers' Perspective. Education Sciences, 10(12):368, 2020. DOI: 10.3390/educsci10120368

[2] Shtaleva N.R., Derkho M.A., Pribytova O.S., Shamina S.V. Distant learning: Challenges and risks of 2020. IOP Conference Series: Earth and Environmental Science, 699 (1), 2021, art. no. 012026.

[3] Fuad M., Akbar M., Zubov L., Deb D. Out-of-class activities: What have we been doing and how we can change it for the future. Proceedings of the14th International Conference on Computer Science \& Education (ICCSE), August 19-21, 2019, Toronto, Canada, pp. 714-719. 
[4] Ho I.M.K., Cheong K.Y., Weldon A. Predicting student satisfaction of emergency remote learning in higher education during COVID-19 using machine learning techniques. PLoS ONE, 16 (4), 2021, art. no. e0249423.

[5] Cicha K., Rizun M., Rutecka P., Strzelecki A. COVID-19 and Higher Education: First-Year Students' Expectations toward Distance Learning. Sustainability, 13:1889, 2021. DOI: $10.3390 / \mathrm{su} 13041889$

[6] Coman C., Țîru L.G., Meseșan-Schmitz L., Stanciu C., Bularca M.C. Online Teaching and Learning in Higher Education during the Coronavirus Pandemic: Students' Perspective. Sustainability, 12:10367, 2020. DOI: 10.3390/su122410367

[7] Rodriguez-Segura L., Zamora-Antuñano M.A., Rodriguez-Resendiz J., Paredes-García W.J., Altamirano-Corro J.A., Cruz-Pérez M.Á. Teaching Challenges in COVID-19 Scenery: Teams Platform-Based Student Satisfaction Approach. Sustainability, 12(18):7514, 2020. DOI: $10.3390 /$ su12187514

[8] Rizun M., Strzelecki A. Students' acceptance of the covid-19 impact on shifting higher education to distance learning in Poland. International Journal of Environmental Research and Public Health, 17 (18), 2020, art. no. 6468, pp. 1-19.

[9] Radu M.-C., Schnakovszky C., Herghelegiu E., Ciubotariu V.-A., Cristea I. The impact of the COVID-19 pandemic on the quality of educational process: A student survey. International Journal of Environmental Research and Public Health, 17 (21), 2020, art. no. 7770, pp. 1-15.

[10] Revilla-Cuesta V., Skaf M., Varona J.M., Ortega-López V. The outbreak of the covid-19 pandemic and its social impact on education: Were engineering teachers ready to teach online? International Journal of Environmental Research and Public Health, 18 (4), 2021, art. no. 2127, pp. 1-24.

[11] Mailizar M., Almanthari A., Maulina S. Examining teachers' behavioral intention to use e-learning in teaching of mathematics: An extended tam model. Contemporary Educational Technology, 13 (2), 2021, art. no. ep298, pp. 1-16.

[12] Cassibba R., Ferrarello D., Mammana M.F., Musso P., Pennisi M., Taranto E. Teaching Mathematics at Distance: A Challenge for Universities. Education Sciences, 11(1):1, 2021. DOI: 10.3390/educsci11010001

[13] Crampton A, Vanniasinkam T., Milic N. "Vodcasts! How to unsuccessfully implement a new online tool". Interaction in Communication Technologies and Virtual Learning Environments:Human Factors, 2010, pp. 118-128.

[14] Dzenite I., Cernajeva S., Matvejevs A. Use of information technology and ORTUS in mathematical studies for foreign students at Riga Technical University. Proceedings of the 14th International Technology, Education and Development Conference (INTED2020), March 2-4, 2020, Valencia, Spain, pp. 6993-6999.

[15] Volodko I., Černajeva S. Use of mathematical program packages for improving and modernizing teaching mathematics in the Faculty of Computer Science and Information Technologies in Riga Technical University. Proceedings of the 16th International Scientific Conference - Engineering for Rural Development (ERDev 2017), Latvia University of Agriculture, Faculty of Engineering, vol.16, 2017, pp. 242-247.

[16] Kristapsone S. Zinātniskā pētniecība studiju procesā (Scientific research in the study process). Rīga: Turība, 2008. 225 p. (In Latvian).

[17] Alreck P., Settle R. Survey Research Handbook. 3rd edition. McGraw-Hill Education, 2003. 496p.

[18] Gamage KAA, Silva EKd, Gunawardhana N. Online Delivery and Assessment during COVID-19: Safeguarding Academic Integrity. Education Sciences, 10(11):301, 2020. DOI: 10.3390/educsci10110301 